\title{
Roundtable
}

\section{Anti-Aging Teleconference: What is Anti-Aging Medicine?}

\author{
PARTICIPANTS: ROBERT ARKING, BOB BUTLER, BRIAN CHIKO, MICHAEL FOSSEL, \\ LEONID A. GAVRILOV, JOHN EDWARD MORLEY, S. JAY OLSHANSKY, \\ THOMAS PERLS, RICHARD F. WALKER
}

\begin{abstract}
The concepts of "anti-aging" and "anti-aging medicine" in particular are hotly debated now, both in the mass media and among some researchers. This paper represents an open discussion of anti-aging terms and related ideas by nine leading experts in the field of aging studies, and it describes in detail the arguments presented by both supporters and opponents of these concepts. Candid exchange of opinions makes it clear that more efforts are required before a consensus on these issues can be reached. The paper also presents evidence that the term "anti-aging" is routinely used now in scientific literature as a legitimate scientific term, including even the titles of publications in reputable scientific journals, written by established researchers.
\end{abstract}

\section{INTRODUCTION}

\section{"A} NTI-AGING MEDICINE" is a concept with more argument that clinical substance, but one with enormous promise and implication. Unjustified claims prompt many to rail against commercial ventures, inspiring more demagoguery than rational discussion. Aging is natural but, for most of us, undesirable. Unfortunately, our human inclination to avoid logical reasoning is also natural, but just as undesirable and perhaps even more unproductive.

Recently, for example, one of our academic discussants (from a prominent and famous institution) enjoyed a recurrent diatribe against a fellow discussant. He had justified his position on the basis of his extensive list of publications (an ad hominem argument). The target of his wrath quietly pointed out that what mattered in argument were data, facts, and logic, not reputation, publications, or intelligence. The second discussant (who spoke more than a dozen languages, had perfect GRE scores, and had once rejected faculty positions at Stanford, Yale, and the University of Michigan in favor of a quieter life) then accurately pointed out that one's background was no more guarantee of omniscience than were long list of publications (which both had). The relevant question was one of rational argument, not prior achievement. Oddly enough, the first discussant concluded that the second discussant had "delusions of grandeur". Seldom had we seen psychiatric double talk used to justify an ad hominem argument. So much for logical discussion and the use of empirical data. 


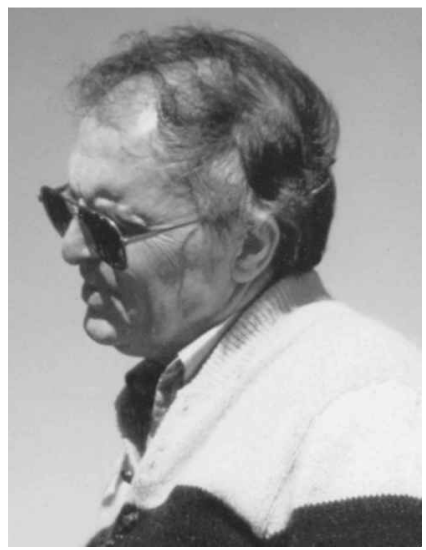

Bob Butler is President and CEO of the International Longevity Center-USA; Professor of The Mount Sinai School of Medicine; and Founding Director of the National Institute on Aging.

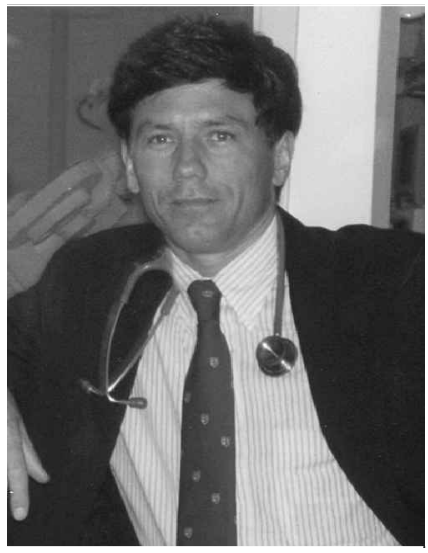

Michael Fossel received his MD and PhD from Stanford, where he held an NSF fellowship and lectured in psychology, neuroanatomy, and medicine. Currently the editor of the Journal of Anti-Aging Medicine, he has been the executive director of the American Aging Association, has lectured worldwide, has taught in several universities, and is currently Clinical Professor of Medicine at Michigan State University. He has numerous publications, including the best selling Reversing Human Aging and his upcoming Oxford University Press textbook Cells, Aging, and Human Disease, an academic exploration of the genetic and cellular mechanisms underlying all human age-related diseases (as well as their prospects for intervention), including 4,250 references, 150,000 words, and two dozen figures.

Leonid A. Gavrilov, Ph.D. is the Editorial Board member of the Journal of Anti-Aging Medicine, journal "Experimental Gerontology", the Scientific World Journal, and a referee (reviewer) for 19 scientific journals. He is a Research Associate at the Center on Aging, National Opinion Research Center, University of Chicago, and a Principal Investigator of the project "Biodemography of Human Longevity" supported by the National Institute on Aging (USA). His scientific credentials are described in more detail in "Who's Who in Science and Engineering," "Who's Who in Medicine and Healthcare," and "Who's Who in America" (Marquis Who's Who).

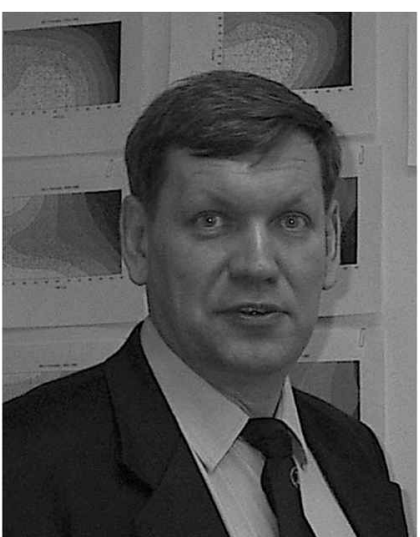

Brian Chiko: Photo and bio were unavailable at press time. 
John Edward Morley completed his medical degree at the University of Witwatersrand in Johannesburg, South Africa in 1972. He is board certified in internal medicine, endocrinology, and geriatric medicine and has edited 16 books and has published over 850 papers. He has received numerous prestigious awards and was among the 100 most-cited authors in the world from 1980 to 1988 . He is editor of the geriatrics section of the yearbook of Endocrinology. He edits the geriatrics section of Cyberounds. In January 2000 he became the Editor for the Journal of Gerontology: Medical Sciences. He has been an invited speaker at many key industry meetings. $\mathrm{He}$ is the medical director of four nursing homes.
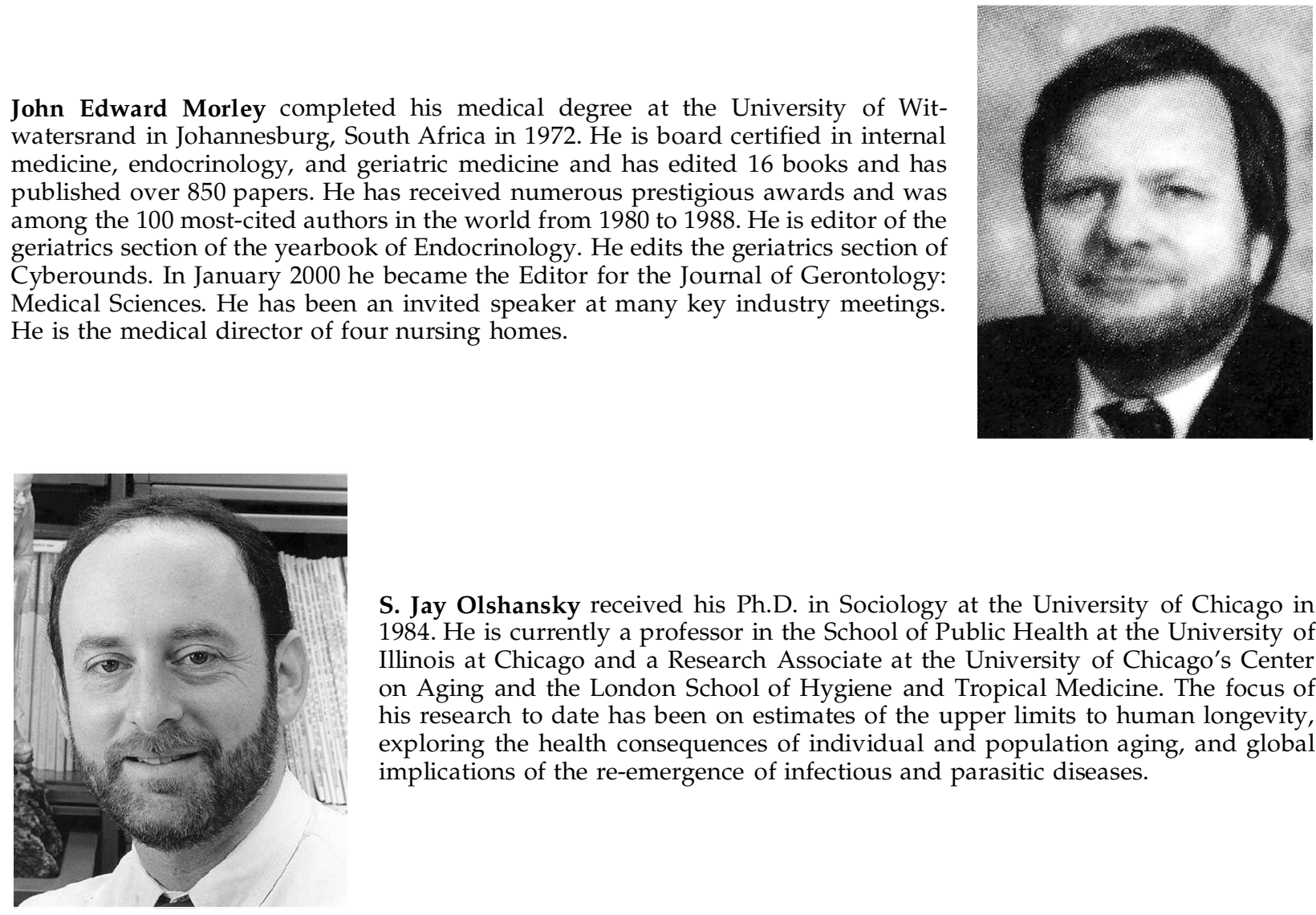

S. Jay Olshansky received his Ph.D. in Sociology at the University of Chicago in 1984. He is currently a professor in the School of Public Health at the University of Illinois at Chicago and a Research Associate at the University of Chicago's Center on Aging and the London School of Hygiene and Tropical Medicine. The focus of his research to date has been on estimates of the upper limits to human longevity, exploring the health consequences of individual and population aging, and global implications of the re-emergence of infectious and parasitic diseases.

Thomas Perls M.D., M.P.H. is Associate Professor of Medicine at Boston University School of Medicine and is Director of the National Institutes of Health funded New England Centenarian Study.

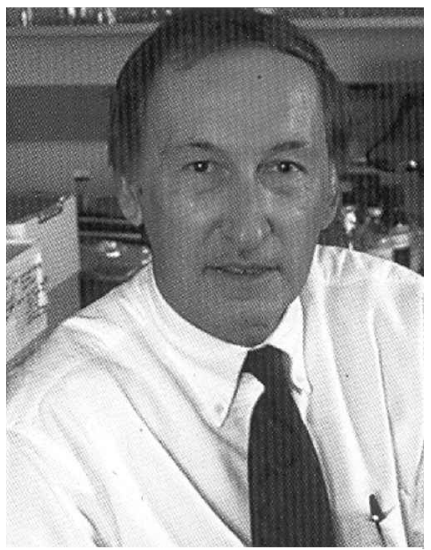

Richard F. Walker, Ph.D., is Research Professor of Biochemistry and Molecular Biology at the University of South Florida and currently serves as Senior Clinical Editor for the Journal of Anti-Aging Medicine. He worked in aging research for over 30 years at institutions such as Duke University Medical Center for the Study of Aging and Human Development, and the Sanders-Brown Research Center on Aging, University of Kentucky College of Medicine where he was tenured Associate Professor. He received support for his research from the NIH, NSF and DOD as well as from private industries and agencies. 
The same uncontrolled emotional tenor often permeates discussions of the ethics and implications of anti-aging medicine (see this issues's editorial), resulting in occasionally bizarre positions implying an almost medieval justification for and acceptance of human suffering and disease. The fault, however, derives not merely from a lack of logic and compassion, but from totally ignoring our lack of semantic agreement. Aging means "biological senescence and increased pathology", but to many people it also means "a gain in perspective, experience, and maturity". While the former has little to recommend it and the latter a great deal, we confute the two meanings and then wonder why we disagree, so irrationally and even viciously. The same problem occurs in discussing "“anti-aging medicine", a term that variously means "research into biological senescence", "a field of clinical endeavor which aims to prevent and cure age-related disease", "interventions which may improve secondary age-related biomarkers", "products claiming to affect aging", and even "the snake-oil market". It is this latter problem, the meaning of anti-aging medicine, that prompted us to bring together disparate discussants in the field. What, we asked our discussants, is anti-aging medicine?

Several of those we invited were unable to join us, as it was difficult to schedule a dozen prominent people from around the world for a single hour together. Nonetheless, those joining us represented not only different backgrounds and different institutions, but divergent opinions. Our discussants are from academic, biotechnology, and clinical venues. Some are vociferous proponents of anti-aging and its remarkable clinical potential, while others rail against frequently fraudulent claims and intentional exploitation of a credulous public. The only common thread among our discussants was a passionate interest in the field and, finally in the truth.

\section{TELECONFERENCE}

MICHAEL FOSSEL: I want to put out two suggestions for beginning this discussion. The first is a series of questions. One is, "Is there any effective anti-aging medicine now?" I think we all have strong answers to that one. Will there ever be? And what about in the labora- tory or with animal models as opposed to clinical interventions; that is, laboratory anti-aging or aging interventions in the laboratory, in vitro, for example. The second issue that comes up is, "Are there different venues in which the term may be valid while it's not in another one." For example, what about discussing this from the standpoint of biotech, as in Brian or Venture Capital, versus medical/clinical use, versus academic investigation versus commercial ventures, such as a number of things actually.

JAY OLSHANSKY: Actually, the first question you asked was, "Is there any anti-aging medicine in existence?" I think it goes right to the heart of the issue that you're trying to get at, and that is, "What is anti-aging?" I thought that that would be a good point for discussion.

RICHARD WALKER: Let me jump in on that. I think the semantics are important. I think the issue of anti-aging is generally assumed to be increased in absolute lifespan. I think that before we make that assumption, we should look at a reflection of the possibility that life extension could include within the biological limits as well as outside of the biological limits. If you look first at within the biological limits or population longevity, then we can say, yes, in fact, anti-aging medicine-if you want to use that term-has been effective in increasing lifespan during the past century. During the next century-or during this current century-it's going to increase it dramatically. If we go beyond that into extension of absolute lifespan, that's a future endeavor, and I think it's quite different from what we're talking about here.

MICHAEL FOSSEL: Let me ask you a question about what you just said. You said that anti-aging medicine is an extension of lifespan. Seat belts extend lifespan, but I don't think that they are anti-aging medicine. Would you like to clarify?

RICHARD WALKER: Yes. In terms of extension of lifespan to biological limits, safety measures like seat belts, of course, would work, but when we look at the causes of death in terms of medical perspective, initially and in the early parts of the past century, based on extrinsic disease, as antibiotics and other therapies have come to sort of minimize extrinsic disease/intrinsic disease, diseases of internal disorder have become dominant. Now we're 
working on that. Effectively preventive medicine-the process of "let's go to the very basics," reducing free radicals, preventing cell damage, and stuff like that-will extend the time before the intrinsic diseases appear. So that approach to reaching absolute limits of biological life is quite different from wearing seat belts. So that's what I'm talking about. Also, the fact that most people in our society, even our Western society, are considered old. AARP starts at 50 . We're not even halfway to the biological limits. So when we're talking about anti-aging medicine, at the most elemental level we can start talking about that which would achieve maximal age within the biological domain. Then we can talk about the other subject, about going beyond that.

MICHAEL FOSSEL: Jay, you said that it's largely a semantic issue as well, though, and that's part of what we' re talking about now, not only what we can do in the lab, but what we call it. Do you want to comment?

JAY OLSHANSKY: Yes. I think there is a real problem with the definition here. If we exercise and modify our diet, we can reduce our risk of a variety of diseases and perhaps in many cases extend duration of life. Have we altered the basic biologic rate of aging at all with any of these interventions? I think that that would be a highly questionable assumption. So I think it's important to distinguish between interventions that might intervene in the basic biological rate of aging itself and interventions that influence the manifestations of aging, such as preventive medicine, which might influence the expression of diseases at any age. I think it's important to distinguish between those two. I think that actually is a fundamental difference in the way in which some people look at the notion of anti-aging medicine and others. Certainly, it's a fundamental difference in the way in which I look at it and the way in which others look at it.

RICHARD WALKER: Would you deny what I proposed in my opening argument, that population longevity or acquisition of absolute limits of biological life is not anti-aging medicine?

JAY OLSHANSKY: First of all, I don't know what absolute limits to biological life are that you're talking about. I don't know that there is such a thing as a basic biological limit to the duration of life that evolved under the direct force of natural selection. Since I don't really believe that such limits exist, I'm not quite sure what you're referring to.

MICHAEL FOSSEL: Let me ask something a little clearer. Let's say that we talked about 120 years-even arbitrarily-no more than that. Or let's say 100 years as sort of a limit for what we expect to get in the near future. Let's say we assume that? Is anything up to 100 years antiaging medicine, or is it only things greater than 100 years or whatever figure you pick like that. Let's say that we pick an arbitrary figure around that. Is anti-aging medicine on one side, the other, or both?

RICHARD WALKER: Let me just say to Olshansky's comment, it's true that we don't know what the absolute limits are of biological life-human biological life-but let's talk about that now anyway. We know that, beyond certain ages, frailty becomes a very significant factor in terms of survival. I think Fossel's comments about 120 years as an arbitrary number are fine because we don't expect humans to live even in the best conditions much longer than that. I go back now to Fossel's comments. I say anti-aging medicine-at least one component of it is within this limit of 100 years or 120 years. There is another component that we'll talk about maybe later.

LEONID GAVRILOV: I would like to support Jay Olshansky with the statement that there is no limit to human lifespan, and there is nothing weird in this statement. It's very simple. It's statistics. If you study the age-dependence of mortality rate, you'll find that, at extreme old ages, the phenomenon of aging apparently disappears: mortality rates are extremely high, but they do not increase much further with age. For example, centenarians $(100+$ years) have extremely high death rates, so that about half of them die each year, but these death rates do not increase much further with age. Their survival curves follow the same pattern as described by the law of radioactive decay. For the law of radioactive decay, from statistics, it follows that there is no fixed limit for lifespan, so you can measure the half-life time, but you cannot determine the absolute maximal age, which separates possible values of lifespan from impossible values. I understand that this may sound as a paradoxical statement, but that's demography and that's 
statistics. More detailed justification of this concept can be found in the book The Biology of Life Span: A Quantitative Approach, section 4.2, "Is there a Species-Specific Life Span Limit?" (Gavrilov and Gavrilova, 1991).

RICHARD WALKER: If that was valid Leonid, then you would expect there to be at least some representatives of 500-year-olds and 1,000-year-olds around.

LEONID GAVRILOV: No. This paradox is well discussed in the standard textbooks of probability theory, such as An Introduction to Probability Theory and its Applications, written by W. Feller. You can estimate the probability of a given longevity record, and then when you know the population size, you'll find that even the longevity claim for Jeanne Calment (122 years and 5 months) is, in fact, implausible. This statistical paradox was recently discussed in the journal Population and Development Review (Gavrilov and Gavrilova, 2000). People cannot live so long, not because they cannot pass a fixed bounding age limit, but simply because the probability of riding out the ever present risk of death for that long is infinitesimal. So, although there is no fixed limit that separates possible numbers of lifespan from impossible numbers, simply because of statistics it is quite implausible to have such a long lifespan. This longevity record is suspicious from the point of view of probability theory. Thus, if you apply probability theory, it explains nicely why the absence of the fixed limit to lifespan is perfectly compatible with the absence of 500-year-olds and even 122-year-olds around.

BOB ARKING: I would like to first agree with Leonid about the probability function of longevity, but I would also like to get back to what Jay said about definitions. They are actually important. I think in the conversation that we've had here, we're mixing together several concepts, both aging and senescence. They're all mixed in with longevity limits and things like that. I think it's important to understand what aging is. Aging, as I use it-I may be a minority of one-is a time-independent series of particular deleterious changes that occur in the post-reproductive era and lead to a loss of function-a decreased loss of function. They can be measured, at least in the lab, by changes in biomarkers or gene expression changes. Then, the processes that drive the change from one stage to the next are, in fact, senescence processes. Given that you defined this as a time-independent series of changes that are correlated ideally with loss of function, then in fact you can measure aging. The question as to whether there is anti-aging science or anti-aging medicine presupposes another question: can we, in our flies, in our worms, or in our patients measure (slow down) the rate of loss of function by some intervention? If we can do that and measure it, then in fact there is an antiaging effect. If you can't do that, then there isn't.

MICHAEL FOSSEL: So what you're saying is that, when Tom Perls in his clinic sees patients dying, they may be dying statistically, but they are not dying of statistics. There is something a lot deeper going on.

BOB ARKING: Oh, in terms of what Leonid said, a rare event (living to 125 or some other large number), is clearly a very rare event. You need a starting size of population to make a rare event become possible. Maybe someone can live to 200 years. Maybe not. I don't know. But in our present state, it's a function of the population at risk.

MICHAEL FOSSEL: Is anti-aging then just a matter of trying to alter the statistical probabilities?

BOB ARKING: No. I think anti-aging would be trying to slow down the rate of change.

TOM PERLS: Just about the semantics briefly. A very basic question for this conference is addressing the appropriateness of the term "anti-aging medicine." I think that, with the American Academy of Anti-Aging Medicine $(\mathrm{A} 4 \mathrm{M})$ and other high-profile entities, it does pay to be very careful about what we call it. To me, the use of the word "medicine" is just another attempt at adding credibility to what I believe is mostly quackery. Instead of calling it "anti-aging medicine," I feel pretty strongly about calling it "anti-aging quackery." The reasons for that are twofold really. One is that the term "anti-aging," I believe, has the ultimate effect of being "anti-old." In its marketing, the American Academy for Anti-Aging Medicine juxtaposes young, very fit-looking people, against their image of old 
people, that of very frail individuals in wheelchairs staring at nursing home walls. So, they have this extremely pernicious message of being anti-old and that you need to do everything you can to not be old. On the other hand, I propose that there can be a very, positive, enabling view of aging - a fountain of aging well, as opposed to a fountain of youth. The second point is that the term "medicine" lends a feeling of credibility that the field does not deserve. The field should be really thought of in two ways: it is made up of those who are claiming they have products that stop and reverse aging when the science does not substantiate their use and the products could potentially be quite dangerous. Then there are the scientists who are doing good work who are not making those claims. But I think, for that reason, "medicine" should not be attached to the term "anti-aging." If we want to look at anti-aging in terms of looking at the basic biology of what's going on and what we do to intervene with that, that's a different term to start thinking about that.

LEONID GAVRILOV: I have made some search for the term "anti-aging" in scientific literature to determine the current status of this term in science. I have found more than 300 scientific articles that use the term "anti-aging" either in titles, key words, or abstracts. This is, of course, an underestimate because many more articles using the term "anti-aging" are not detected by MedLine/PubMed search if this term is used in the main body of text, but not in the title, key words, or abstract. The content analysis of these publications is really interesting. Some of the recent articles do criticize the abuse of this term, which takes place outside the scientific domain ("in the wild"), but most of the scientific articles are using the term "antiaging" as a self-explanatory legitimate term, which does not require any justification. What is particularly interesting is that sometimes the term "anti-aging" is put even in the titles of the articles as a legitimate term (over 40 scientific articles) in such reputable journals as Science and Proceedings of the National Academy of Science of the United States of America. There are at least 26 professional journals and editions that use this term as a legitimate one, even in the titles of their publications:
Aging-Clinical and Experimental Research (Milano)

Annals of the New York Academy of Sciences

Biogerontology

Bioscience Reports

Cellular and Molecular Life Sciences

Clinical and Experimental Pharmacology and Physiology

CNS Drug Reviews

Ethnopharmacology

Experimental Gerontology

Expert Opinion on Therapeutic Targets

Immunology Letters

International Journal of Biochemistry \& Cell Biology

International Journal of Neuroscience

Journal of Anti-Aging Medicine

Journal of Gerontology

Journal of Nutrition

Health \& Aging

Journal of Reproduction and Fertility

Mechanisms of Ageing and Development

Medical Hypotheses

Microscopy Research and Technique

Novartis Foundation Symposium

Obesity Research

Proceedings of the National Academy of Sciences of the United States of America

Science

Scientific American

Toxicologic Pathology

When you look for the authors who put the term "anti-aging" as a legitimate term in the title of their publications, you will find that these are reputable scientists such as Steve Austad, Donald Ingram, Edward Masoro, Arlan Richardson, George Roth, and Richard Weindruch. [Here is a partial alphabetic list of 18 particularly prominent scientists, who used this term as a legitimate one in the titles of their publications: S.N. Austad, E. Bergamini (Italy), B.F. Clark (Denmark), R.G. Cutler, A.D. de Grey (U.K.), A. Everitt (Australia), A.R. Hipkiss (U.K.), D.K. Ingram, K. Kitani (Japan), D.L. Knook (Netherlands), M.A. Lane, E.J. Masoro, J. Meites, S.I. Rattan (Denmark), A. Richardson, G.S. Roth, R. Weindruch, and B.P. Yu]

I would be delighted to be on a team with such good scientists! [Anyway, the results of this bibliographic study are now published in the form of an article with a self-explanatory 
title: "Scientific Legitimacy of the Term 'AntiAging.' (Gavrilov, 2002). In updated form, the results of this bibliographic study are also available at the following website: www.src.uchicago. $\mathrm{edu} / \sim$ gavr1/antiaging-publications.html.]

Thus, we can conclude that the term "antiaging" is accepted now as a legitimate scientific term by reputable journals and established researchers. This term is routinely used now in scientific literature (like the terms "anti-oxidant" or "antibiotic," for example).

The term "anti-aging" is also accepted as a legitimate term by at least five dictionaries and encyclopedias, including the most recent Encyclopedia of Aging, published by Macmillan Reference USA (Ekerdt, 2002).

You can also find this term in the medical dictionary, where it is listed as an adjective to describe interventions "used or tending to prevent or lessen the effects of aging" (www2.merriam-webster.com/cgi-bin/mwmednlm?book= Medical\&va=antiaging).

The American Heritage ${ }^{\circledR}$ Dictionary of the English Language, 4th ed. (2000) also mentions "anti-aging" as an adjective to describe interventions "delaying or lessening the effects of aging" (http://www.bartleby.com/61/34/A0333450. html).

This term is also accepted by the MerriamWebster Dictionary (www.m-w.com/cgi-bin/ dictionary?va= antiaging).

In some cases, claims are made that the term "anti-aging" is an oxymoron, because the notion of aging prevention defies fundamental laws of physics and chemistry. The "experts" who make such claims really need to educate themselves by reading, for example, the article "Antiaging Agents," published in the recent Encyclopedia of Chemical Technology (Kroschwitz and Howe-Grant, 2001).

Yes, it is true that this term is abused outside the scientific domain ("in the wild") by charlatans and quackery. So what? Charlatans are always doing this with any other term and idea that can be attractive and profitable. For example, there are great abuses over sex, drugs, and money, but nobody suggests eliminating the terms "sex" and "drugs" from biology and medicine, as well as the term "money" from economy.

MICHAEL FOSSEL: Let me point out two things. One is that we've just taken a turn. We're no longer talking really about whether there is really anything that affects aging. We're talking about the use of the term. I'm glad we changed that. You're defending it on the grounds that it's in use, whether we like it or not, whether you think it's a good term or not. It's in use. Let me point out the opposite of that. Brian Chiko represents, I think, the interests in some ways of venture capital and biotech. They don't use the term for a similar very practical, very pragmatic reason. It's not useful fiscally. Brian, can you comment on that?

BRIAN CHIKO: Yeah. Briefly, I agree wholeheartedly with Tom Perls. I think, if you look at most of the biotech companies they have really evolved to not adopt any of the current nomenclature that's used, such as "anti-aging." It's been used for so long by high-profile organizations such as the A4M that really have negative undertones and some very questionable practices. So to avoid that association or that connotation is a goal of any company seeking recognition and significant amounts of capital to develop drugs that will ultimately be FDA approved. When you get a drug approved through the FDA, you need to be addressing a disease and not aging, because aging isn't recognized as a disease. So, any new drug that comes out that does address aging will never be identified as that, certainly not initially.

TOM PERLS: The reason I like the term "preventive medicine" so much is because society can get so much more bang for its buck by looking at the older years beyond the age of 60 as a period of time that we should all be taking advantage of and that we should maximize in terms of our health. Public health measures, especially education, would facilitate many more people to live to older age-that is, to live to their mid-to-late 80s, compressing their morbidity toward the end of their lives, living a long period of time beyond the age of 60 in good health. Strength training, achieving a lean weight, an appropriate diet, not smoking, and other strategies such as these would have a tremendous benefit, in terms of doing much of what I think a lot of people in this conversation would like to see happen. But as long as we continue to feed into things like what A4M is doing (i.e., giving a negative view of aging), 
people will fall for the anti-aging quackery. They will reach for the things that these hucksters promise, rather than exert the significant effort and will required to get to older age in good health and take advantage of what should be a wonderful time for us. I just think that the term "anti-aging" combined with a credible term like "medicine" is counter to the goal of getting many more people in good health at an older age.

MICHAEL FOSSEL: Let me just underscore what you said by pointing out that there is no Journal of Anti-Alzheimer's, or anti-cancer, or anti anything else that people don't like. For that reason, the publishers and I have talked for a long time about changing it to the Journal of Aging Medicine. Again, the decision hasn't been made, but it is, I think, along some of the lines that you've just raised.

RICHARD WALKER: Can I jump in here in terms of the practicality on both sides of this issue. I have been in this field a long time. I don't think that I ever heard the term "anti-aging medicine" until the 1990s. I don't know who coined the term, but it may very well have been Klatz and A4M. Whether it's used or not in the literature now is somewhat irrelevant. But in fact, a decade before that there was a group out of California, who are also entrepreneurs, Pearson and Shaw, I believe, who jumped on Catia's work showing that L-dopaand also Wertman's work-extended life in experimental animals. That didn't have much relevance to the general public, because it didn't relate to humans. I think the significance of "anti-aging medicine," the term, is that it linked to Rudman's clinical studies and so therefore had a greater impact on the general public. But the initial thing that I started mentioning when we began this discussion was, in fact, a realization of life within biological limits. We don't have to argue about what that means, but I do agree with Tom in terms of what he just said. Anti-aging medicine, in terms of what we would all agree is realization of a good quality of life within the lifetime that we have, the difference between the other organizations who promote sensationalism is they counterpose pictures of youthful people, young people, against older people. In fact, these interventions that we attempt will never make an 80-year-old or even a 50-year-old look like a 20-year-old. They'll make you look like a good 50-year-old compared to a bad 50-yearold or a healthy 60 -year-old compared to an unhealthy 60-year-old.

BOB BUTLER: This would probably be a good time for me to make a few comments. I've been listening-and I came in late. I apologize if I wind up saying some things that have already been said. Well, I'm pretty much in Tom's corner and agree with what Jay had also said. But I wanted to point out that we have done a survey recently-actually, a cross-national survey, in other countries too-and people don't believe in anti-aging medicine. I think it's maybe useful to point that out. When asked if there are possibilities of retarding, stopping, or reversing aging, the public isn't quite as unaware as one might fear.

[SPEAKER UNKNOWN]: I have to disagree with you.

BOB BUTLER: You're not disagreeing with me. I'm talking about data from a poll on American representative data. That doesn't mean that there aren't some who do believe it. I'm just reporting a poll. I think that something like 20\% thought there might be something to it. I could send you the data if you'd like. The second point I wanted to make relates to culture and history. We have given up terms and science before, like "phlogiston," for instance. There are terms that have been extremely negative and used before like "abiotrophy" and "degeneracy." When I first had the responsibility of starting the National Institute on Aging, there was a very vibrant group that called themselves Life Extension-which I might just add parenthetically turned out to be extremely difficult because they were perceived as so irrational by members of Congress, that people, for example, like Fritz Hollans of South Carolina did not want to support the National Institute on Aging because they were afraid it would be too perilously close to these strange people out there. So, there is a real danger in the use of terminology or the expression of notions for which we don't have any basis. The third point I would like to make is that this is really now under considerable legal pressure, both within Congress and the government accounting office. There are a lot of moves to- 
wards possible revision of the 1994 Dietary Supplement and Health Education Act. So there may be some remedies in store here. It is, I think, another good reason to disassociate gerontology in general from the concepts of socalled "anti-aging medicine." The next point I would like to quickly make is that we don't have biomarkers of aging, so the FDA has no way to even judge any putative claimed agents that retard or reverse aging. Finally, I think that the one thing that seems to unify much of what everybody has said is the prospect that there are preventive health methods, as Tom points out. There are behavioral aspects, and there is the prospect in the long view of being able to get some understanding of senescence. So I have always thought that maybe a positive term like "longevity medicine" might carry some weight that's not carried-and without the bad freight that "anti-aging medicine" carries.

MICHAEL FOSSEL: Bob, you and I have had this discussion before. What is different between longevity medicine and just plain ordinary good internal medicine? I'm not sure there is a difference.

BOB BUTLER: Most internists don't talk to their patients frankly about good health habits.

MICHAEL FOSSEL: I think Tom Perls does.

BOB BUTLER: Some do. But I would say a great many physicians spend very little time, from study after study, even talking about tobacco cessation. So there isn't much going on in standard practicing medicine that's very behavior oriented or preventive oriented unfortunately.

MICHAEL FOSSEL: Are you just saying then that internal medicine is failing its patients?

BOB BUTLER: On the preventive side, yes. You know, part of it is I don't totally blame them. Some of it has to do with reimbursements, time pressures, and HMO. I recently had a modest illness and saw my doctor, and he saw me for about three minutes. That's about all he had time to see me.

JOHN MORLEY: I think a reasonable thing to point out is that the reason geriatrics developed is that internists don't do the things that are good for preventing frailty or for improving quality of life in older people.

BOB BUTLER: Correct.
JOHN MORLEY: All my internal medicine colleagues tell me they are great geriatricians because most of their patients are old. However, when I get to see their patients, they are not doing the geriatric principles on the whole because you can't do those in a short period of time. So I think there is a place for geriatric medicine. I don't know that there is any need to invent another 22 terms for this area. We've got "gerontology" - which is a bad term most probably-and "geriatric"-which is an equally bad term. But we could live with those because those are the official terms that have been adopted by the two very legitimate societies, I think, that exist in this area. To me, it seems that the problem with anti-aging is what everybody is sort of saying. It has got a bad name. To perpetuate something with a bad name allows people to sell themselves as doing anti-aging. You can't sell yourself as a geriatrician if you haven't certified. I think there is a big difference. If you're certified as an antiaging physician, which I believe you can't do, I think that's fine. But I struggle with the concept that they have certified in anything that is useful. But perhaps I'm wrong.

MICHAEL FOSSEL: Let me point out that the American Medical Specialists Group will not take anti-aging medicine as a specialty, nor will they ever, where geriatrics is an accepted specialty. So when they say it's a specialty, that's by self-definition, not by any other accepted definition.

TOM PERLS: I think it was Walter who recently said in the conversation that we'll never be able to take an 80 -year-old and make them look or be like a 40 -year-old or a 50-year-old. Speaking a little bit for the Kronos Institute and Mitch Harmon, I think that a lot of the research that they're aiming for is that they do, in part, have this lofty goal of, "Yeah, we think we could do something like that." They think that, if people did not set their sights high, we would never get a space shuttle out into orbit. But realize that, when some people say that someday we will see a lot of people achieve age 150, I do think that's kind of like thinking we're going to get some people out to Pluto, whereas I do think if we could get a lot of people getting to their mid-to-late $80 \mathrm{~s}$ in good health (not to Pluto but rather in orbit around the Earth), that 
would be akin to devoting the resources that have been put into something like the space shuttle program. With regard to getting people who are 80 act, feel, and look like they are 50 , I'll just give a quick example. When I was on the wards recently, I came across an 80year-old man who was looking pretty good except for a medical condition he was there for. Sitting next to him was his 70-year-old wife, who I at first thought was his daughter. Subjectively, she looked like she was in her early 50 s to me. She just looked remarkable. I'm not saying that older people don't look remarkable too, but just in terms of what I'm used to seeing in terms of some subjective markers of aging. My hope is that, with the science we're doing, we're going to start dissecting out some of the reasons people age so differently. When I further asked what was going on there, it turned out that she had an aunt who lived to be 100 and another relative, who had been in our study, actually verified to be age 114 . It was quite amazing. I think that there should be some credence, some good science that's done responsibly to start looking at the reasons why people can age so differently and begin to look at the basic biology. However, to allow the anti-aging snakeoil salesmen to somehow attach themselves to good, responsible science doesn't seem like something we should be trying to do.

JOHN MORLEY: I guess the real question is, "Do we need the word anti-aging as a legitimate word?" All of this can be done in the rubric that is already there.

TOM PERLS: I agree.

JOHN MORLEY: The point of getting another name, whether it's "longevity medicine" or "anti-aging," is because you think it will bring funding in some way or another. I mean, that's really the only usual purpose for inventing a new term that I can see when there are reasonable terms already there. I think that we should stick to the terms that are there and work to increase the awareness of how we treat people to prevent frailty, how we treat people to make them do better. If I go back 40 years and we look at pictures of people in their early 60 s, they looked really old. They looked like many of the modern 80-year-olds. I think Bob Butler is a great example. I mean, Bob looks like he's 22 compared to me. [Laughter.] I think that we're moving towards that.

JOHN MORLEY: But I think the real question is, "Do we need a term, or do we need to say that this is a term that should not be used by legitimate practitioners?" That would be one way to solve the problem of the illegitimate out there.

JAY OLSHANSKY: There are plenty of clinicians out there currently working in what they refer to as anti-aging or longevity clinics, who claim to have adopted principles of anti-aging medicine, when, in fact, what they're selling is basic preventive medicine mixed with a combination of hormones and antioxidants. Then you have the legitimate research scientists who are trying to understand the puzzle of aging and find ways to intervene in it. I think the terms "anti-aging" and "anti-aging medicine" have been used by both. I think when the clinicians are selling preventive medicine as antiaging medicine, it is a misuse of the concept. I think that the intent in many cases is to improve the health of their patients, but I think, in other instances, these clinicians are just out to make money. There are plenty of organizations out there like this that are designed to make six-figure incomes for clinicians who are selling anti-aging medicines to their clients. The problem, in part, is the way in which it's been misused by some and used appropriately by others. Perhaps-and I know we discussed this at the meeting in Tucson, Bob; I think it was last year; you came up with, what was it?longevity science and medicine.

BOB BUTLER: As a possibility.

JAY OLSHANSKY: Something like that. The problem is that, while the term itself may not date back that far, the concept goes back thousands of years. It's been misused. It's been sold to the public. It's tainted by quackery and hucksterism. While there may be legitimate scientists who insert the term into the titles of their manuscripts for legitimate research, I think that the term itself is really misused and, I think, suffers terribly. My personal feeling is that we should be substituting it with something else.

LEONID GAVRILOV: May I comment on this issue? I have studied how the term "longevity medicine" is used now, to see whether it is less abused by charlatans, compared to the term 
"anti-aging." I have done this study for the following reasons. When we wrote a consensus paper in Science, together with Aubrey de Grey, Michael Fossel, Jay Olshansky, and four other researchers, we expressed the following concerns: "The term 'longevity science and medicine' was recently introduced by a group of scientists now working in the field, but the fear remains that this term will be co-opted by the pseudoscientific antiaging industry as well" (de Grey et al., 2002). Our concerns proved to be prophetic. That's exactly what happened. Now if you just type "longevity medicine" in the Google search engine, you will find that this term is extensively abused. All these "miracle" drugs, supplements, and procedures, including growth hormone, dehydroepiandrosteron (DHEA), melatonin, and herbs, are now being sold to the public as "longevity medicine." Moreover, the American Academy of Anti-Aging Medicine has recently established the American Board of Longevity Medicine and Science, which "adds to your credibility by offering certification in longevity medicine" (www.worldhealth.net/index.php?p= 200). Now every person who can afford to pay $\$ 645$ to $\mathrm{A} 4 \mathrm{M}$ and meet their requirements can be certified in longevity medicine. So they are in fact very quick, because for them it is just a matter of choosing the next sexy word. Now, I am receiving e-mail spam advertisements suggesting you can become 20 years younger, which use the terms "biotechnology" and even the "Bioterrorism Personal Protection Plan," exploiting the most recent fears of the American population. It is simply impossible to compete with these masters of spam, and if we choose to avoid words just because somebody abused them, we will be mute. We will have no words to say. Now may I also comment on another issue. One of the arguments against the use of term "anti-aging" in the title of our journal is based on the belief that there is no precedent for using the prefix "anti" in the titles of scientific journals: for example, it is believed there is no scientific "anti-cancer" journal. I have studied this issue and found that in fact there are at least four legitimate scientific "anticancer" journals:

Anti-Cancer Drug Design (ISSN: 02669536; Publisher: Oxford University Press)
Anti-Cancer Drugs (ISSN: 09594973; Publisher: Lippincott, Williams \& Wilkins)

Anticancer Research (ISSN: 02507005; Publisher: International Institute of Anticancer Research)

Journal of Anti Cancer Agents (ISSN 0167-6997); Publisher: Kluwer Academic Publishers)

I have also found that terms such as "antiAlzheimer drugs" and "anti-Parkinson drugs" are routinely used now even in the titles of scientific articles, so it may simply be a matter of time before these terms appear in the titles of scientific journals too.

Other scientific journals using the prefix "anti" in their titles include the following:

Antiangiogenic Agents in Cancer Therapy (Publisher: Cancer Drug Discovery and Development)

Antibiotics and Chemotherapy (Publisher: S. Karger Ag )

Antiinfective Drugs and Chemotherapy (Publisher: European Society for Biomodulation and Chemotherapy)

Antimicrobial Agents and Chemotherapy (Publisher: American Society for Microbiology)

Antimicrobic Newsletter (Publisher: Elsevier Ltd.)

Antimicrobics and Infectious Diseases Newsletter (Publisher: Elsevier Ltd.)

Antioxidants $\mathcal{E}$ Redox Signaling (Publisher: Mary Ann Liebert Inc.)

Antioxidants in Health and Disease Series (Publisher: Marcel Dekker Inc.)

Antisense and Nucleic Acid Drug Development (Publisher: Mary Ann Liebert Inc.)

Antiviral Chemistry \& Chemotherapy (Publisher:

Blackwell Science Ltd)

Antiviral Chemistry and Chemotherapy (Pub-

lisher: Blackwell Group)

Antiviral Research (Publisher: Elsevier Ltd.)

Antiviral Therapy (Publisher: International Medical Press)

Journal of Antibiotics

Journal of Antimicrobial Chemotherapy (Oxford University Press)

International Journal of Antimicrobial Agents

Thus, it is perfectly acceptable to use the prefix "anti" in the title of a scientific journal. 
This bibliographic study also alleviates some concerns that the term "anti-aging" could be misinterpreted as being against aging persons (ageism). We know for sure that the term "anticancer" does not mean being against cancer patients-quite the opposite! Exactly the same reasoning is applicable to "anti-aging" - it is targeted against the destructive aging process with the intention to help older people to stay in better shape and to enjoy a productive life.

JAY OLSHANSKY: I tend to agree with Leonid. I think he is right here. No matter what term we come up with, you know that people at some of these organizations are simply going to substitute that word or phrase for whatever phrase they are currently using. Tom Perls and I talked about this in New York a couple of months ago. I thought Tom really had a great suggestion. If you remember, Tom, I asked you about this very issue. Your response was, "Well, perhaps we should reserve anti-aging medicine for researchers who are doing legitimate scientific work in the area and use the phrase 'The anti-aging industry' to refer to those who are selling potions to the public under the false pretense that it's somehow possible to modify the biological rate of aging today." I thought that that was a particularly useful idea. In other words, we (as scientists) redefine what they are selling as inappropriate.

RICHARD WALKER: But we have no control over the use of the word. I understand how we're trying to work with semantics here, but in fact, it's been said several times that there is no way to prevent other people from using the words in the way that they mean. I think it's incumbent on us to understand what we are talking about. I think in the closing statements, Michael said that we would have a chance to sort of summarize it, so I'll save my comments for then. I think that if one were to discriminate between anti-aging medicine and the antiaging industry, it would be within our own literature. It would really be irrelevant to the general public. I think that "anti-aging medicine" persists, and it permeates not only the public, but the medical community. I have had the opportunity for the last three years to be outside of the academic arena and actually see how many physicians in this country and outside of the country, recognize anti-aging med- icine or feel that anti-aging medicine is an area. They recognize $\mathrm{A} 4 \mathrm{M}$ as being the authority, unfortunately, in that area. So it's incumbent on us to present a legitimate side to that. I don't know how that would finally be accomplished, but that's our task, more than worrying about splitting hairs on names, I think.

TOM PERLS: Reasonable and good scientists who have used the term "anti-aging medicine" in the past might have done so in a lackadaisical manner, not realizing the unwarranted credibility they lend to the marketing of this industry. Now we need to combat the use of the term, and to say loudly and clearly that there is no such thing, and to say that the anti-aging industry and its purveyors are hucksters. My goal would be not to work with it, but to point out that the people who use this term are trying to lend credibility to an otherwise dangerous message and field. I don't think it's a matter of, "If you can't beat them join them." I think it's much more the case of "We've got to beat them" and to stop them cold.

MICHAEL FOSSEL: It's about time to start pulling this to a close, unfortunately. Let me ask each one of you to make any summary comments you'd like to. Also, if any one of you, in doing so, want to make any suggestion for an alternate title to the journal, we'd sure like to hear it. Normally, at this point, I think I would just start down the list with Tom. But since Tom just finished talking, let me jump to the bottom of the list and move up. John Morley.

JOHN MORLEY: I think my summary is that the word "anti-aging" has bad connotations, that we have legitimate areas of research in science, both in using the terms "geriatrics" for medicine and "gerontology" for science, that we should not look for new terms, that we should publicize fairly broadly that the use of terms like "anti-aging," while not always associated with bad science, often are. But at the same time, we should recognize that sometimes what we do within legitimate medicine is not necessarily good science. We have to look within as well. Certainly, we have had major problems with the pharmaceutical industry in these areas. So I think that we have to be very careful, but I don't think that we should be looking for anything new at this stage, but 
rather to try and continue to legitimize what we already have.

BOB BUTLER: My main interest is the preservation of the best of science. I agree that any term, including the one that I had been thinking of-"longevity medicine" and "longevity science" - can be misused. Maybe it's premature to introduce anything new. But "anti-aging," for the reasons so well described by Tom and everyone, is an exceptionally bad term. From my point of view, since we have a government relations office here at the International Longevity Center, we're going to try to pursue ways in which the Dietary Supplement Health Education Act can be modified to be made more stringent. We're going to be thinking about ways in which the FDA can be advised that there are no biomarkers of aging and therefore some question about the so-called interventions that would either slow, retard, or prevent aging don't exist. And any other cooperation with the GAO or other organizations that speak to this. We're taking it very seriously in terms of what might be accomplished in order to avoid what, I think, is well described as the "anti-aging industry."

RICHARD WALKER: I don't think we would be talking today if "anti-aging medicine" didn't have large name recognition and have significance in the general population, as well as in the academic and medical communities. I think the name, good or bad-and I agree with everyone who said that there are tainted sides to this and bad sides to this-still has significant name recognition, and there is good work going on in the area. I think preventive medicine obviously is anti-aging medicine because it brings us to enjoy longer and better quality of life within the biological limits. Let me just say I disagree with Tom who said that an 80-year-old can look like a 50-yearold. I think that that 50-year-old appearance would be very good, I'm sure, but if you stood her next to a healthy 50-year-old, there would be a significant difference. I think when it comes to rejuvenation or maintenance of a younger phenotype, we're going to have to get into genetic interventions where we actually stop the process of change. Right now, we're in a replacement therapy mode. I think that's ev- idenced by the fact that I just received a mailing today from the American Association of Clinical Endocrinologists entitled "Preventive Endocrinology." Well, in the years that I've been in this area in experimental endocrinology and physiology, it's only recently that I have seen the idea of replacing hormones rather than treating specific symptoms and diseases. I'll just close with that.

BRIAN CHIKO: Yes. From the biotech perspective, "anti-aging" is not an acceptable term for the long list of reasons that people have already noted. I think there won't be a true industry in which people are shipping products that actually delay or improve maximum longevity for at least 5-10 years. So I think renaming isn't a big issue right now. I think that avoidance of the term "anti-aging" is a tactic most of us take.

LEONID GAVRILOV: The term "anti-aging" is a legitimate scientific term accepted by reputable scientific journals and established researchers. This term has a clear self-explanatory meaning, and it is routinely used in scientific literature like the terms "antioxidants" and "antibiotics," for example. So, it is perfectly fine to use such names for scientific journals such as "Journal of Anti-Aging Research," or anti-aging studies, or anti-aging science.

The term "anti-aging medicine" is more controversial, because it may create the wrong impression that a cure for aging has been found and can be made available to patients. Still, this term could be used if we put a clarifying disclaimer at the front pages of our journal. We all understand that anti-aging medicine is the ultimate goal (medicine of the future) of legitimate scientific research published in our journal. Why not to say this explicitly? We just need a short clarifying disclaimer published in each issue of our journal in its front pages ("mission of the journal"). Just two or three clarifying sentences may be sufficient to separate us from anti-aging quackery.

The question is whether we would follow the five-year tradition of our journal or for some fiscal or legal reasons would change the title. That's not my decision. I just convey to you the information regarding scientific legitimacy of the term "anti-aging." Political decisions are 
not where I'm an authority. What I would like to say is that it is important to be fair to our fellow scientists who already use the term "antiaging" in their publications, and not to harm them by discrediting this term. For example, the web site of Brian Chiko is advertising the following damaging and incorrect statement: "If it's 'anti-aging,' it's quackery by definition (www.juvenews.com/ qa.html\#terminology). Of course, it does not help our fellow researchers who use this term in their scientific work, publications, and research proposals. This citation is quoted at the website as the opinion of Dr. Jay Olshansky, published in Science, but as far as I understand, this is not exactly his opinion now. So, we should not harm our fellow researchers, and if they already use the term "anti-aging," we should at least respect their choice. I believe we can all agree with the final conclusion of our consensus letter published in Science: "we urge the scientific and lay population to be sure that they understand that there are currently no scientifically proven antiaging medicines, but that legitimate and important scientific efforts are underway to develop them" (de Grey and Gavrilov et al., 2002).

JAY OLSHANSKY: My goodness. We're all here because we're excited about aging and aging research. I think that there is something to be very excited about. Ongoing research that I have seen in the past decade, I think, is terribly exciting. I personally am very enthusiastic about the prospect that, at some time in the future, we may be able to intervene in some way in the aging process of humans. We can't do it today, but perhaps some time in the future. Juxtaposed to that exciting research is a rather large and rapidly growing industry that has been called "anti-aging medicine" by A4M and by a number of other organizations. I think that it is critically important to distinguish between the two. Personally, I don't see preventative medicine as the same as anti-aging medicine. I don't think it should be sold under that terminology, although I think it certainly is. I don't know whether or not the adoption of a new term would make any difference at all. I really don't know. I suspect that a new term would probably be obfuscated by those who are sell- ing anti-aging products. But I think it's incumbent upon us as scientists to clearly distinguish between the exciting ongoing research in the field and the anti-aging quackery that is out there today.

TOM PERLS: There is no such a thing as antiaging medicine, so why use the term. There is such a thing, however, as anti-aging quackery. And the term "anti-aging quackery" should be popularized in every way we can so that it gets the public to think and second guess these hucksters. "Anti-aging medicine" is dangerous in terms of its pernicious view of older people, and it is dangerous because many of the things that are advertised by these individuals are not proven to work and can be dangerous. The term "anti-aging medicine" has become prevalent in our society because of hucksterism and a huge amount of marketing dollars. I do not think that it is well accepted by the responsible academic medical community, and if it is perceived as such, it is, again, because of the hucksterism and the marketing dollars. I don't want my statement about 80 -year-olds versus 50 -year-olds taken out of context. I simply wanted to point out that aging is extremely heterogenous. People age very differently from one another and have different susceptibilities to diseases associated with aging. Part of gerontology and geriatrics is trying to understand how and why people are like that, and to try to understand the underlying causes and reasons. That's the science I want to help promote.

BOB ARKING: It seems to me that there is a valid field of anti-aging science. There is no valid field today of anti-aging medicine. There is an anti-aging industry, as has been pointed out, which is not based on any scientific-or any good-scientific principles. I was interested in the point that Tom, Bob, and Brian brought up, that perhaps the most deleterious combination is that term of "anti-aging medicine." So that could be a problem. We could look for other terms- "anti-senescent biology and medicine," "longevity biology and medicine." There are others out there. But they would probably co-opt in that sense. So perhaps I think it was Tom and Brian's suggestion-and Jay's-that we should make very clear what constitutes valid science, and how 
and when they can translate that into a practical medical environment, and point out, as appropriate from time to time, that the industry is not based on any scientific principles.

MICHAEL FOSSEL: Thanks Bob. I'll just close by saying a couple of things. One is, I think you're right, Bob. There is such a thing as a field, whatever we call it. The name is either wrong, or at the very least, has significant costs in lots of ways. I think that most of us would agree that there are interventions that are effective in aging, at least in vitro or in certain animals. I think that most of us here would agree that very few of those interventions have much clinical benefit or, at the very least, have very little proven clinical benefit. On the other hand, there are certainly interventions that sell. Retin-A may or may not effect aging, but to the public's mind, it affects something that they associate with aging and don't like. I don't think we're ever going to change either the perception or the desire to buy those kinds of things. Finally, the journal, whatever we end up calling it, has a lot of different sorts of readers. We have biotech industry workers and scientists and clinicians and the general public. It is difficult, if not impossible, to address all of the different ways of looking at these things.

\section{REFERENCES}

De Grey ADN, Gavrilov L, Olshansky SJ, et al. Antiaging technology and pseudoscience. Science 2002;296:656.

Ekerdt DJ, (ed). Encyclopedia of Aging. New York: Macmillan Reference USA, 2002.

Gavrilov LA. Scientific legitimacy of the term "anti-aging." J Anti-Aging Med, 2002;5:239-240.

Gavrilov LA, Gavrilova NS. The Biology of Life Span: A Quantitative Approach. New York: Harwood Academic Publishers, 1991.

Gavrilov LA, Gavrilova NS. Validation of exceptional longevity. Population Dev Rev, 2000;26:40-41.

Kroschwitz JI, Howe-Grant M, eds. Kirk-Othmer Concise Encyclopedia of Chemical Technology, 4th ed. New York: Wiley-Interscience, 2001.

$$
\begin{array}{r}
\text { Robert Arking } \\
\text { Department of Biological Sciences } \\
\text { Wayne State University } \\
\text { Detroit, MI } 48202
\end{array}
$$

E-mail: rarking@biology.biosi.wayne.edu 